Cita: Henríquez Salido, María do Carmo (2006): "La calidad y censura de las voces en el DRAE-1791: la marca forense", en Mar Campos Souto e Ignacio Pérez Pascual, eds., El diccionario de la Real Academia Española: ayer y hoy, A Coruña, Universidade da Coruña, Anexos de Revista de Lexicografía, 1, pp. 141-153. https://doi.org/10.17979/spudc.9788497497466.141

\title{
La calidad y censura de las voces en el DRAE-1791: la marca forense*
}

\author{
MARÍA DO CARMO HENRÍQUEZ SALIDO \\ Universidade de Vigo
}

(cc) BY-NC-SA

\section{INTRODUCCIÓN}

Tal y como se da a conocer en la «portada» ${ }^{1} \mathrm{o}$ «fachada» de la obra y se anticipa en el «Prólogo» de la tercera edición del Diccionario de la lengua castellana de la Real Academia Española (1791), son dos las ideas principales sobre las que se basa la reimpresión: (a) la primera, entroncada con la difícil realidad del trabajo lexicográfico, trata de conseguir la triple finalidad de corregir «los defectos que había notado» en el $D A$ (tarea en la que había empezado a trabajar «aun antes» de la publicación del sexto

* Este trabajo se inscribe en el marco del Proyecto de investigación «Jurisprudencia, léxico y terminología jurídica» de la «Consellería da Presidencia e Administración Pública» de la "Xunta de Galicia» (PGDIT01PXI30202PR), que se lleva a cabo en el Departamento de Lengua Española de la Universidad de Vigo, con la colaboración de D. Enrique De No Alonso-Misol, magistrado de la Sala de lo Social de la Audiencia Nacional. No damos pormenores bibliográficos del $D A$, por haberlo hecho ya en nuestro estudio (Henríquez 2004), ni de estas dos ediciones del diccionario académico, que se pueden ver, entre otros, en Alvar Ezquerra (1993), Álvarez de Miranda (2000), Azorín (2004), Haensch (1997), Ruhstaller (2003), que incluye referencias bibliográficas comentadas, o Zamora Vicente (1999). En los ejemplos del texto modernizamos la acentuación, pero en las citas respetamos escrupulosamente los originales. Hemos utilizado para el $D R A E-1780$ y el $D R A E-1783$ la edición en DVD-ROM de la Real Academia Española (1999); para la tercera hemos manejado el original, que nos ha cedido gentilmente, el conde palatino de Rodriavia, y abogado en Ribadavia, D. Camilo Rodríguez Alonso.

1 Diccionario/ de la lengua castellana / compuesto / por la Real Academia / Española, / reducido á un tomo / para su mas fácil uso. / Tercera edicion, / en la qual se han colocado en los lugares correspondientes todas las / voces de los suplementos, que se pusiéron al fin de las ediciones de los / años de 1780 y 1783, y se han intercalado en las letras D. E. y F. nuevos / artículos, de los quales se dará un suplemento separado./ [...] 
y último tomo), incorporar todas las voces de los suplementos, que se habían puesto al final de las ediciones de 1780 y 1783, e intercalar en las letras D, E y F nuevos artículos; y (b) la segunda pretende ofrecer al público en un solo tomo, como en las dos ediciones anteriores, un diccionario completo de fácil manejo y a un «precio cómodo» -destaca Zamora Vicente que la «Academia ha considerado siempre este ángulo de los precios» (1999: 373)-, de acuerdo con el plan que había diseñado «para proceder con acierto y uniformidad así en la corrección como en el aumento», «pero sin quitar ninguna voz, ni alterar la obra en cosa substancial». Además de estas dos ideas, los miembros de la Corporación hacen notar que «en la calidad y la censura de las voces» se usan varias abreviaturas (como la forense que emplean desde 1780):

y deseando hacerle de mas fácil uso, y que el Público pudiese tenerle por un precio cómodo, determinó reducir los seis tomos á uno solo; pero sin quitar ninguna voz, ni alterar la obra en cosa substancial.

Para poderlo conseguir, pareció preciso valerse de todas las economías posibles, y así se ha impreso en un tomo en folio á tres columnas por llana y con letra pequeña, pero muy clara y limpia. En la calidad y censura de las voces se ha usado de varias abreviaturas [...] («Prólogo», DRAE-1791: V-VI).

Una de las peculiaridades evidentes del DRAE-1791 (además de las tres columnas de $7 \times 31 \mathrm{cms}$. por página; letra «muy clara y limpia», y la supresión de autoridades, de etimologías y de anomalías de los verbos) es el registro de voces y acepciones con una marca que las asigna al tecnolecto forense, que no presentaban esta información contextual en el $D A$. De las dos abreviaturas que la Institución usa para «distinguir» el vocabulario de las Ciencias jurídicas -For. («forense») y Jurisp. («jurisprudencia»)- la primera es la que se ve con más frecuencia y, aunque no hemos realizado el recuento de voces y acepciones con marca de jurisprudencia, los ejemplos parecen ser escasos (consolidación, inforciado ...). La lectura de la obra permite comprobar, además, que en el dominio específico forense se incluyen voces que el $D A$ había advertido sobre su uso en «lo curial» (antipoca, antipocar, aventaja), en el «Derecho» (fundo, regresso), «en lo legal» (excepción), «entre los jurisconsultos» (tantear), «entre juristas» (terminante), «entre jueces, relatores y abogados» (abigeato), «en los tribunales» (dubio) o vocablos catalogados como «término jurídico» (indotación) y «término legal» (apartamiento); se mantienen, no obstante, «indicaciones complementarias» en el texto de la definición o al final del texto definidor, para señalar el uso de carácter no regular de una determinada unidad léxica en los campos forense o jurídico, expresadas con comentarios del tipo «en lo forense» (absolver las posiciones, álveo), «tiene uso en lo forense» (a mayor abundamiento, fallar), «suele usarse en lo forense» (traspasación), o «úsase más 
freqüentemente en lo jurídico» (inalienable), «úsase freqüentemente en lo jurídico» (variante), etc. ${ }^{2}$

En este trabajo nos proponemos analizar la postura de la Academia, en la última década del siglo XVIII, respecto al tratamiento del vocabulario científico, que pertenece al ámbito de la actividad profesional de «jueces, relatores y abogados», es decir, sólo las voces y acepciones con marca de forense, y hacer un cotejo con el tratamiento de que había sido objeto en el primer diccionario académico. Estudiamos, en primer lugar, el «aumento» que, por razones de espacio, limitamos a la adición de artículos y de acepciones correspondientes al lema principal o a formas complejas (o definiciones que contienen indicaciones sobre el uso como las mencionadas en el párrafo precedente), $\mathrm{y}$, en segundo lugar, examinamos la «corrección», esto es, las enmiendas introducidas a partir del examen y dictamen de los académicos sobre «la calidad y censura de las voces», ${ }^{3}$ que circunscribimos a determinados elementos de la nueva organización de la microestructura del artículo lexicográfico. Este estudio pretende ser complementario del anterior (Henríquez 2004, r: 763-773), en el que demostramos que en el $D A$ existía una explícita intención de utilizar indicaciones en el artículo lexicográfico, con las que se suministrase información sobre las circunstancias o restricciones de uso de determinadas piezas léxicas, con el fin de advertir sobre aquellas voces «cuyo uso es solamente admitido en el estilo forense».

\section{EL «AUMENTO» DE ARTÍCULOS Y DE ACEPCIONES}

Los redactores de la reimpresión explican en el «Prólogo» cómo se ha llevado a cabo la «corrección» y el «aumento». Las letras A y siguientes hasta la F inclusive «se han puesto con la corrección y aumento que tienen en el tomo primero de la segunda impresión, y en el segundo y tercero»; «la G y demás letras restantes van

2 Estas indicaciones o advertencias sobre el uso en lo forense presentan modelos diversos: «úsase más comunmente en lo forense» (acumulación); «regularmente se usa en lo forense» (pesquisa); «en lo forense se llama» o «se llama en lo forense» o «llaman en lo forense» (probar la coartada, intervención, vehemente); «dícese más comunmente en lo forense» o «en lo forense se dice comunmente» (pasar en autoridad de cosa juzgada, radicación); «así en lo forense» (interlocutoriamente); «en lo forense se aplica» o «se aplica en lo forense» o «aplícase en lo forense» (enormísimo, petitorio, plenario, preventivo, troncal); «en lo forense significa» (exabrupto); «en la práctica forense» (legalizar)... Las fórmulas utilizadas para referirse específicamente a la frecuencia de uso son: «úsase poco fuera de lo jurídico, ó forense» (yusión), «tiene más uso en lo forense» (apertura), «es muy usado en lo forense» (definitivo; otro sí; solvente, ó solviente), «se usa más freqüentemente en lo forense» o «úsase freqüentemente en lo forense», «úsase muy freqüentemente en lo forense» (desestimiento, subrogación, subrogar, turbativo), etc.

3 Los académicos definen la calidad como «la propiedad natural de cada cosa, por la qual se distingue de las otras» y entienden por censura «el dictámen y juicio que se ha hecho de alguna obra, ó escrito despues de haberla conocido y exâminado». 
sin aumento, ni corrección como están en el Diccionario antiguo, pero alterada la ortografía»:

Las letras A y siguientes hasta la $\mathrm{F}$ inclusive, se han puesto con la correccion y aumento que tienen en el tomo primero de la segunda impresión, y en el segundo y tercero, que aunque enteramente concluidos, están todavía inéditos, [...] La G y demas letras restantes van sin aumento, ni correccion como estan en el DICCIONARIO antiguo; pero alterada la ortografia, y conforme á las últimas reglas que ha establecido la ACADEMIA («Prólogo», DRAE-1791: v).

Los artículos añadidos, respecto a los del $D A$, no son muchos; hemos contabilizado una cifra ligeramente superior a treinta. La mayoría corresponden a voces de la letra A (acumulativamente, adir la herencia, administratorio, agir, agnaticio, aguijatorio, alimentario, antidoral, apertura, arbitratorio, arras, arrogación) y de la letra C (casador, caucionar, cesante, probar la coartada, comparte, concesionario, confieso, consignar, contrafirmante, contrafirmar, convicto). En la letra E computamos cuatro ejemplos (emplazo, encartado, entramiento de bienes, excusión), en la letra D tres (desexecutar, desinsaculación, dividuo), en la letra B un único ejemplo (beneficiario) y ninguno en la letra F. Todos están en la edición de 1780, excepto comparte, que aparece en el $D R A E$-1783. Las palabras, que dan entrada a estos artículos nuevos del DRAE-1791, corresponden a las letras D y E (desexecutar, desinsaculación, dividuo, emplazo, entramiento de bienes y excusión). Las acepciones, que se presentaban como subentradas o «entradillas nuevas», aparecen ahora agrupadas bajo una única entrada y no se observan cambios en los sentidos que adquieren las palabras en determinados contextos, conforme se puede comprobar al confrontar artículos como el que encabeza el lema arras. ${ }^{4}$

Los casos de inserción de la abreviatura ante una definición, que en el $D A$ no aparecían con esta clase de indicación, arrojan una cifra próxima al centenar. Suelen documentarse en la descripción de voces que los redactores habían tomado de textos

4 «ARRAS. s. f. ant. Lo que se daba por prenda, ó señal de algun concierto. Extendíase tambien al contrato matrimonial. [...]

ARrAS. p. Las trece monedas que en las velaciones sirven para la formalidad de aquel acto pasando de las manos del desposado á las de la desposada. [...]

ARRAS. for. La cantidad que el varon promete á la muger por razon del casamiento con ella, y no puede exceder, según ley, de la décima parte de sus bienes. [...]» (DRAE-1780).

«ARRAS. s. f. ant. Lo que se daba por prenda, ó señal de algun concierto. Extendíase tambien al contrato matrimonial. [...]. 2. Las trece monedas que en las velaciones sirven para la formalidad de aquel acto pasando de las manos del desposado á las de la desposada. [...] 3. for. La cantidad que el varon promete á la muger por razon del casamiento con ella, y no puede exceder, según ley, de la décima parte de sus bienes. [...]» $(D R A E-1791)$. 
de carácter jurídico, o en la de vocablos, en cuya definición se incluían comentarios que advertían de su uso en el Derecho, o se decía que eran «términos jurídicos», «términos legales» o «voces de los juristas». Las acepciones de lemas comprendidos desde la letra A hasta la $\mathrm{C}$ inclusive, excepto cesionario, ria-que está en el DRAE1783 pero sin marca- ya se recogen con esta abreviatura en el $D R A E-1780$. El método consiste en anteponer esta marca a la definición ya existente en el DA (apelación, apelar, citatorio, comparición, compulsión, compulsorio...) o en añadir nuevas acepciones marcadas al lema principal, como se ve al cotejar en el $D A$, en el $D R A E-1780$ y en el $D R A E-1791$ la explicación de voces como abdicar o acriminar. ${ }^{5}$

Estas acepciones marcadas pueden pertenecer a lemas, que encabezan un artículo simple, por ser de uso específico en lo forense (abigeato; abigeo; acusatorio, ria; adir la herencia; agnado, da; agravatorio, ria; amovible; antipoca; capturar; citatorio, ria; comparición; compulsión; compulsorio, ria ...), a un lema principal con varias acepciones (acceso, apartamiento, apelación, apelar, asesor, caución, causídico, consignar, corruptela ...) o a formas complejas (adición de la herencia; amparar en la posesión; aprehender la posesión; carta de comisión; caso de corte; caución juratoria; cédula ante diem; condición imposible de derecho; constar en autos, o de autos; constituir apoderado; cosa juzgada; curador ad litem...).

Las acepciones con marca diatécnica, referentes a voces de las letras D hasta la F inclusive, no se encuentran ni en el $D R A E-1780$ ni en el $D R A E-1783$, por lo cual son acepciones nuevas. Pueden corresponder, así mismo, a lemas que encabezan un artículo simple, por ser de uso específico en lo forense (declinatoria; derogatorio, ria; desistimiento; dubio; emplazador; encartado; estatuir; feudista...), a un lema prin-

5 «ABDICAR. v.a. Quitar, ò revocar la acción, ò facultád à otro concedida. Es voz antigua usada en Aragón. [...]» $(D A)$.

«ABDICAR. v. a. Dexar, ó renunciar enteramente. [...] Es voz modernamente introducida en esta significacion $[\ldots]$

ABDICAR. for. Renunciar de su propia voluntad el dominio, propiedad, ó derecho de alguna cosa. [...] ABDICAR. for. $A r$. Anular, revocar la accion, ó facultad concedida á otro. [...]» (DRAE-1780).

«ABDICAR. v. a. Dexar, ó renunciar enteramente. [...] Es voz modernamente introducida en esta significacion [...] 2. for. Renunciar de su propia voluntad el dominio, propiedad, ó derecho de alguna cosa. [...]. 3. for. Ar. Anular, revocar la accion, ó facultad concedida á otro. [...]» (DRAE-1791). «ACRIMINAR. v.a. Acusar, ágria y vehementemente, como delito y maldad, la acción que no lo es, ò hacerla mas grave de lo que es, exagerándola y ponderándola $[\ldots] »(D A)$.

«ACRIMINAR. v.a. Exágerar, ó abultar algun delito, culpa, ó defecto. [...]

ACRIMINAR. ant. Acusar de algun crimen, ó delito. [...]

ACRIMINAR LA CAUSA. f. for. que vale agravar, ó hacer mayor el delito, ó la culpa; y así se dice: el nuevo exceso, ó la declaracion del reo ACRIMINÓ la causa. [...]» (DRAE-1780).

«ACRIMINAR. v.a. Exâgerar, ó abultar algun delito, culpa, ó defecto. [...] 2. ant. Acusar de algun crimen, ó delito. [...] ACRIMINAR LA CAUSA. f. for. que vale agravar, ó hacer mayor el delito, ó la culpa; y así se dice: el nuevo exceso, ó la declaracion del reo ACRIMINÓ la causa. [...]» (DRAE-1791). 
cipal con varias acepciones (divisa, dolo, excepción, excusador, fallo...) o a formas complejas (mandamiento de despojo; carta de emplazamiento...). En las otras letras del libro encontramos: ignorancia (i. de derecho, i. de hecho), indotación, legar, legatario, regreso y triplicar, que también está en el DRAE-1780. Los lemas indotación y legatario encabezan, igualmente, artículos simples, por ser de uso específico en lo forense.

El mayor número de lemas con acepciones marcadas, procedan estas de las registradas en el $D A$ o de las añadidas en esta edición, forman parte del conjunto de palabras de las letras A y C; en la letra D tenemos trece (declinatoria, delegado, derogatorio, descripción, desertar, desinsacular, desistimiento, desistir, despojo, diligenciero, divisa, dolo, dubio), en la letra E nueve (emplazador, emplazamiento, emplazar, encartado, enmendar, estatuir, excepción, excusa, excusador) y en la letra F tres (fallo, feudista, fundo). ${ }^{6}$

\section{LA «CORRECCIÓN» DE ARTÍCULOS}

Una de las enmiendas, puesta de relieve por los académicos, es la que alude al traslado de «varios artículos» de unas letras a otras, lo cual lleva parejo el de la definición de la voz, que se señala con la inclusión de la abreviatura «V.» («Véase»), cuya finalidad es transmitir el mensaje de que una forma compleja está situada en otro lugar del diccionario o que la definición del lema encontrado está en otro artículo:

Según las reglas y plan formado por la ACADEMIA para la correccion del DICCIONARIO, varios artículos deben trasladarse de unas letras á otras. De aquí resulta que algunas voces, que en el DICCIONARIO antiguo se hallan definidas en las letras A y

${ }^{6}$ Las unidades léxicas que hemos extraído son las siguientes: abdicar (con dos acepciones), abigeato, abigeo, abonado (testigo a.), absolver de la instancia, acceso, acriminar, actos, acusatorio, adición (a. en la herencia), agnado, agravatorio, agraviarse, agravio, alegar, álveo, alzada (dar a.), amovible, amparar (a. en la posesion), antipoca, antipocar, apartamiento, apelacion, apelar, aprehender (a. la posesion), apremiar, arbitramiento, asesor, autor, aventaja, capturar, carta (c. de comisión, c. de gracia, c. de libre, c. de pago, c. forera), caso (c. de corte), caucion (c. juratoria), causídico, cédula (c. ante diem, pleyto de c.), cesionario, citacion (c. de remate, ó para el remate), citatorio, probar la coartada, comparicion, compulsion, compulsorio, condicion (c. imposible de derecho, $c$. imposible de hecho, c. mezclada, c. necesaria, c. posible, c. tácita o callada, c. torpe), conocer, consignar, constar (c. en autos, ó de autos), constituir (c. apoderado), contestar (c. la demanda, ó pleyto), corruptela, corte, cosa (pasar en c. juzgada), curador (c. ad bona, c. ad litem), declinatoria, delegado, derogatorio, descripción, desertar, desinsacular, desistimiento, desistir, despojo (mandamiento de d.), diligenciero, divisa, dolo, dubio, emplazador, emplazamiento, emplazar, encartado, estatuir, excepción, excusa, excusador, fallo, feudista, fundo, ignorancia (i. de derecho, i. de hecho), indotacion, legar, legatario, regreso, triplicar. 
siguientes hasta la $\mathrm{F}$ inclusive, en el nuevo están sin definicion en estas letras, y se remiten á otras para definirlas en ellas. Por exemplo, el artículo Bienes profecticios, que en el DICCIONARIO antiguo está definido en la B en la palabra Bienes: en el nuevo, [...] se remite de la B á la P [...] («Prólogo», DRAE-1791: vI).

Este tipo de «corrección», introducida en el entramado microestructural del diccionario, lo vamos a ilustrar con el análisis del vocablo bien. En el $D A$, como es conocido, se utilizaban «letras versales» para representar el lema y «letras versalillas» para las subentradas, que introducían las sucesivas acepciones de la voz. Esta práctica hace que la palabra bien ${ }^{7}$ ( y los refranes) cuente con cuarenta y seis subentradas, siete de las cuales son formas complejas, que muestran notas de uso en el enunciado definitorio: bienes castrenses, o quasi castrenses; bienes divisibles; bienes dotales; bienes emphitéuticos; bienes havidos y por haver, bienes mostrencos y bienes troncales. El DRAE-1791 registra, a partir de la decimoséptima acepción, tres (bienes castrenses, bienes dotales y bienes mostrencos), pero advierte que están definidas en otro lugar del diccionario; las otras cuatro se han suprimido. Tampoco aparecen en los artículos, que tienen como entrada las voces divisible, enfitéutico y haber o habido; solamente en la voz troncal se dice: «lo que pertenece al tronco. Aplícase en lo forense al género de bienes que no se incluyen en la sucesión regular $[\ldots] »$.

Los redactores de la obra ya habían avisado en el «Prólogo», que se podían encontrar «olvidos» o «descuidos» en las remisiones, y uno de ellos podría ser el que

7 «BIEN. s.m. Aquello que en sí mismo tiene el complemento de la perfección tocante à su próprio género, ò lo que es objéto de la voluntád, la qual ni se mueve, ni puede moverse sino del bien, [...]

BiÉnEs CASTRENSES, ò QuASI CASTRENSES. Los que adquiére el hijo de família por medio de la guerra, ò la toga. Es voz forense. [...]

BIÉNES DIVISIBLES. En lo forense se entienden los que no son de mayorazgo.

BIÉNES DOTALES. Los que por razón de dote lleva la muger à poder del marido quando contrahen el matrimonio. Es voz forense. [...]

BiÉNES EMPHITÉUticos. Lo mismo con poca diferéncia que bienes foráles. Vease. Es voz forense. $[\ldots]$

BIÉNES HAVIDOS Y POR HAVER. En lo forense se entienden todos los que hasta entonces se posseen, $\mathrm{y}$ los que se pueden adquirir en adelante. [...]

BIÉNES MOSTRENCOS. En lo forense se llaman assi los que no tienen posseedór conocido, ò heredéro, y por esto recaen en el Príncipe, ò República. [...]

BiÉNes troncales. Los que por algun fuero, ò ley del Réino han de volver siempre al tronco de donde salieron. Es voz forense. [...]» $(D A)$.

«BIEN. s. m. El que tiene en sí la suma perfeccion y bondad; y en este sentido solo Dios es el sumo BiEN [...]. 17. [...] Bienes castrenses. V. Castrense. [...] Bienes dotales. V. Dotal. [...] Bienes MOSTRENCOS. V. Mostrencos. [...]» (DRAE-1791). 
se documenta en el artículo encabezado por $\operatorname{dar}^{8}$ (y darse). Esta voz (sin tener en cuenta los modos de hablar o de decir, las sentencias y los refranes) sumaba en el $D A$ más de doscientas ochenta subentradas, entre las cuales se recogían cuatro formas complejas: dar fiador, o fianza; dar querella, dar término y dar testimonio. En el $D R A E-1791$, sin tomar en consideración las numerosas formas complejas, este verbo tiene dieciocho acepciones, entre las que no figuran las cuatro anteriores. Al consultar las voces fiador, querella, término y testimonio se ve: dar fiador sí está como forma compleja y última acepción de la palabra fiador, pero sin marca que la distinga; la segunda acepción de la voz querella presenta la etiqueta, que avisa de alguna particularidad de uso (querella. for. «la acusación, o queja, propuesta ante el juez contra alguno, en la que se le hace reo de algún delito [...]»); la acepción sexta del vocablo término está marcada (término. 6. for. «tiempo determinado»), y, por último, ninguna de las acepciones del vocablo testimonio aparece con marca de forense. No dejan de sorprender las más de doscientas ochenta acepciones de la palabra dar existentes en el $D A$ frente a las cincuenta y tres acepciones (transitivas 1 a 30, intransitivas números 31 a 47 y pronominales números 48 a 53), sin contar las formas complejas, que reconoce el DRAE-2001.

Otra «corrección» importante, que los académicos no mencionan en el «Prólogo», es la nueva organización de la microestructura del $D R A E-1791$. Si en el $D A$ se dedicaba una subentrada a cada acepción, ahora se sigue el principio de agrupar los contenidos bajo una única entrada. El artículo lexicográfico se estructura así: el lema encabeza el artículo y aparece representado en letras versalitas, sigue de forma inmediata la información gramatical, pueden incluirse o no otras indicaciones (p. ej., «Voz o frase antiquada»), y las acepciones correspondientes al lema van numeradas, si son más de una, a partir de la segunda. Las formas complejas se colocan después de la última acepción numerada; suelen aparecer en primer lugar las combinaciones estables del lema con otros elementos que desempeñan una función adjetiva con respecto a él, después se ponen las frases y los refranes, ordenados, en líneas generales,

8 «DAR. v.a. Donár, ceder graciosamente alguna cosa transfiriendo al mismo tiempo el dominio de ella. $[\ldots]$

DARSE. v. r. Entregarse, rendirse à la voluntad ò razón de otro. [...]

DÁR FIADÓR, Ò FIANZA. Term Forense, que significa presentar ante el Juez sugéto, y bienes, que estén obligados à la paga, en caso de faltar el principal à su obligacion. [...]

DAR QUerella. Term. Forense, que vale Presentar ante el Juéz petición, en que se aléga de agrávios y se pide satisfacción contra algúno que se ha ofendido en la honra, vida o hacienda. [...]

DAR TÉRMINO. Es conceder plazo y señalar tiempo para executar alguna cosa. Usase mas comunmente en lo Forense, adonde passado el término ò plazo perentório que se señala, se incurre en las penas que se ponen. [...]

DAR testimonio. Term. Forense. Es hacer fé el Escribáno de algun contráto que ha passado ante él, poniendo por escrito todo aquello que vió executar, y signado y firmado de su mano se lo entrega à la parte que lo pide para su resguardo. [...]» $(D A)$. 
alfabéticamente. Este tipo de «corrección» lo vamos a explicar con el análisis de la voz carta: ${ }^{9}$ ninguna de las treinta y siete acepciones ( $\sin$ tomar en cuenta los refranes) registradas en el $D A$ contenía en la definición advertencias de uso en lo forense; en el $D R A E$-1791 se documentan cuatro formas complejas, con marca de forense, colocadas a partir de la última acepción numerada, que es la sexta; vienen después las frases (dar cartas), los refranes (Ni firmes carta que no leas [...]) y en último lugar las frases familiares (no ver carta). Otro ejemplo lo tenemos en la voz condición: ${ }^{10}$ en el $D A$ se recogían dos acepciones con información de uso en lo forense; en el DRAE-1791, encontramos siete formas complejas marcadas, ordenadas alfabéticamente a partir de la quinta acepción, que es la última; al final se colocan las frases (poner, o tener en condición).

La supresión de las advertencias de uso en la definición es bastante abundante, pero el número de ejemplos es más bajo que en el caso de los «aumentos». Esta «corrección» se puede efectuar de tres modos: no anteponiendo la abreviatura a la definición, suprimiendo la acepción que debería aparecer marcada o haciendo des-

9 «CARTA. s. f. Papél escrito y cerrado con obléa ò lacre, que se envia de una parte à otra para incluir en él, el negócio, ù matéria sobre que se quiere tratar, y que vaya secreto. [...]

CARTA FORERA, Ù DE GRACIA. La escritúra de privilégio y despacho Real que se dá y concede à uno para que goce de tales ò tales exenciones, fueros, gracias e indemnidades en la República. [...]

CARTA FORERA. Se llama tambien el despacho ò provisión que se conseguía para poner demanda à alguna persóna, sobre biénes, hacienda ù otra qualquiera acción; [...]» $(D A)$.

«CARTA. s. f. Papel escrito y ordinariamente cerrado con oblea, que se envia de una parte á otra para comunicar y tratar unas personas con otras estando ausentes. [... 6. Qualquiera de los naypes de la baraja. [...] CARTA DE COMISION. for. Provision que despacha el tribunal superior cometiendo, y dando delegacion á juez particular para algun negocio, ó causa [...] CARTA DE GRACIA. for. $A r$. Pacto de retrovendendo. [...] CARTA DE LIBRE. for. ant. Lo mismo que FINIQUITO, ó LIBERACION, que los menores dan al tutor concluida la tutela. [...] CARTA FORERA. for. ant. La provision, ó despacho que daba el tribunal superior, segun fuero, y leyes. [...]» (DRAE-1791).

10 «CONDICION. s. f. Natural o génio de los hombres: y assi se suele decir de la persóna que le tiene suave, dócil, blando. [...]

Condición. Significa tambien imposición, gravámen, carga con que se hace algúna donación, ò se dexa algún legádo ò heréncia [...]. En esta acepción es voz forense. [...]

Condición. Postúra, pleito, ò pacto de alguna cosa que está por hacer ò por venir, que empieza con esta palabra Si: [...] En esta acepción es voz forense. [...]» $(D A)$.

«CONDICION. s. f. La naturaleza, ó constitucion de las cosas; y así se dice: esta es la CONDICION de las cosas humanas [...] 5. Calidad, ó circunstancia con que se hace, ó promete alguna cosa. [...] CONDICION IMPOSIBLE DE DERECHO. for. La que se opone á la honestidad, ó á las buenas costumbres, ó al derecho natural [...] CONDICION IMPOSIBLE DE HECHO. for. La que consiste en hecho que no puede cumplirse por la persona á quien se impone [...] CondiCION MEZCLADA. for. La que en parte pende del arbitrio delos hombres, y en parte del acaso, como [...] CONDICION NECESARIA. For. La que es preciso que intervenga para la validacion de algun contrato [...] CONDICION POSIBLE. for. La que está en poder y arbitrio de los hombres [...] CONDICION TÁCITA, ó CALLADA. for. La que aunque expresamente no se ponga, virtualmente se entiende puesta [...] Condicion tORPE. for. La que se opone derechamente a alguna ley. Llámase tambien esta CONDICION deshonesta [...]» (DRAE-1791). 
aparecer en la definición las notas de uso. Cuando se trata de voces de las letras comprendidas desde la $\mathrm{A}$ hasta la $\mathrm{C}$ inclusive, se percibe que, salvo en contadas excepciones (artículos, caso negado...), esta eliminación ya se había llevado a cabo en el DRAE-1780; en las otras letras la supresión se efectúa en el DRAE-1791 (decir, declarante, delegante, derechamente, desapoderar...), aunque hay casos que se apartan de esta regla (decreto, enagenable, estrechamente, pedimento...), pues ya no llevaban esta abreviatura en el DRAE-1780.

El análisis de esta modalidad de «corrección» lo vamos a hacer comparando la descripción de las voces comparecer y condenación en los dos textos. El verbo comparecer $^{11}$ tiene en el $D A$ dos acepciones, en una de las cuales se hace constar, después de la definición, que «en esta acepción es voz forense»; es de ésta de la que se va a prescindir en el $D R A E-1791$. De las cuatro acepciones que se recogen en el $D A$ para la voz condenación, ${ }^{12}$ en la tercera se indica que «en lo forense se entiende y toma de ordinario por [...]»; de estas cuatro sólo dos aparecen en el DRAE-1791 y ninguna presenta una marca que la asigne al tecnolecto forense. Como consecuencia de esta «corrección», el número de acepciones de las que se han eliminado las informaciones contextuales, si nuestro cálculo no es erróneo, alcanza la cifra de setenta y una. ${ }^{13}$

11 «COMPARECER. v.n. Parecer, ò presentarse una persona ante otra, venir personalmente, ò por podéres, al llamamiento, intimacion ò emplazamiento que se le ha hecho. [...]

COMPARECER. Vale tambien venir al llamamiento de Juez competente, para defenderse de algun pleito que se le pone, ò cáusa que se le impúta. En esta acepción es voz forense. [...]» $(D A)$.

«COMPARECER. v. n. Parecer, presentarse una persona ante otra, ó por poder en virtud de llamamiento, ó intimacion que se le ha hecho, ó para mostrarse parte en algun negocio. Comparere»» (DRAE-1791).

12 «CONDENACIÓN. s. f. Senténcia pronunciada por Juez, en que declara por injusta ò ajena de razón algúna cosa, ò que impóne castigo y pena al reo por el delito cometido. [...]

CondenAción. Significa tambien la pena, multa y castigo que se impóne al reo por el delito o culpa cometido. $[\ldots]$

CondenACión. En lo forense se entiende y toma de ordinario por la multa o pena pecuniária que se impóne sobre contravención ò excesso: la qual por ley está destinada à la Cámara ò Fisco Real. [...]

Condenación. Por Antonomásia se entiende la eterna, que procéde del juicio de Dios» $(D A)$.

«CONDENACION. s.f. El acto y efecto de CONDENAR. Damnatio. 2. Por antonomasia se entiende la eterna. Aeterna condemnatio» (DRAE-1791).

13 Las acepciones en cuya definición se ha prescindido de la advertencia de uso en lo forense corresponden a estas unidades léxicas del DA abolición, abolir, abrogación, abrogar, absolución de la instancia, acabarse la candela o candelilla, acumulador, alifara, amortización, aprehenso, arbitrariamente, arráigo, artículos, asserto, auto, ayúda (dar o pedir favor y a.), biénes (b. divisibles, b. emphitéuticos, b. havidos y por haver), calúmnia (juramento de c.), capitulaciones, capitulante, cargo, cargos, caso negado, castrense, chirographário, comparecer, complicidád, condenación, confitente, conocimiento, contestación, dar (d. fiadór, ò fianza; d. testimónio), decir, decisório, declarante, decreto, delegante, denegación (con d.), derechamente (responder y contestar d.), desapoderar, deviedo, devolución, dexación (d. de biénes), dilapidación, dilapidar, elidir, emancipación, emancipar, embargante (no e.), embargos (sin e. de embargos), emphitheutecário, enajenable, enalienable, entablación, enunciar, escribir, estése (a prueba y e.), estrados (citar para e.), estrechamente, ficto (confessión f.), institución de heredero, mejóra, pedimento, postulación, prevención, queja, subsidiário, supervención. 
Además de la exclusión de dichas advertencias (abrogación, abrogar, acumulador, arraygo, aserto, ayuda...), se documenta que en algunos artículos se ha simplificado la redacción de las definiciones de los sentidos de la voz, que sirve de entrada, con el empleo de paráfrasis del tipo 'acción y efecto de V', 'acción de V', 'que V', 'calidad de N', precedidas del determinante: amortización «la acción de amortizar», capitulante «el que capitula», complicidad «la calidad de cómplice», contestación «la acción y efecto de contestar», dexación «la acción y efecto de dexar», emplazador «el que emplaza», excepción «la acción y efecto de exceptuar»...

\section{Consideraciones finAles}

Hemos analizado en las páginas anteriores el «aumento» de voces y de acepciones marcadas y la «corrección» de determinados elementos de la microestructura del DRAE-1791. Como resultado de nuestro estudio, formulamos estas conclusiones provisionales:

$1^{\text {a) }}$ En el $D R A E$-1791 se confirma el propósito de la Academia de transmitir la información de que determinadas voces «se distinguen» de las otras, porque pertenecen a un campo del saber y de la actividad profesional de «jueces, relatores y abogados». Esta clase de información se señala, casi de modo «uniforme», con la abreviatura «for.» antepuesta a la definición; aunque esta suele ser la regla, se mantienen todavía «indicaciones complementarias» en la definición, expresadas con comentarios diversos, para distinguir el uso de carácter no regular de determinadas piezas léxicas.

$\left.2^{a}\right)$ La Academia consolida una codificación de marcas como la forense, en la que se incluyen voces, que el $D A$ había advertido su uso «en lo curial», en el «Derecho», «en lo legal», «entre los jurisconsultos», «entre juristas», «entre jueces, relatores y abogados», «en los tribunales», y vocablos catalogados como «término jurídico»o «término legal». Esta marca se va a mantener hasta la decimonovena edición (DRAE-1970: XXVIII).

$3^{\text {a) }}$ El «aumento» de artículos alcanza una cifra ligeramente superior a treinta; la mayoría se corresponden a lemas de las letras A y C. Los casos de inserción de la abreviatura ante el enunciado definitorio, que en el $D A$ no contenía especificaciones de uso en lo forense, se aproximan al centenar, pero estos «aumentos» ya están registrados, casi en su totalidad, en el DRAE1780 . 
4 ${ }^{a}$ Hemos analizado la «corrección» de determinados aspectos de la nueva organización de la microestructura y la supresión de las notas de uso de definiciones, fruto de la «censura» realizada por los académicos. Del total de las cuatrocientas cincuenta y cinco acepciones con información de uso en lo forense, que contabilizamos en esta nueva lectura del $D A$, se han suprimido setenta y una. A pesar de estas «correcciones», el DRAE-1791 experimenta un «aumento» de voces y acepciones marcadas: los tecnicismos forenses alcanzan un número superior al medio millar (quinientos doce), cifra próxima a la de quinientos setenta y dos, que es la facilitada por Azorín (2002: 785) respecto al DRAE-1843.

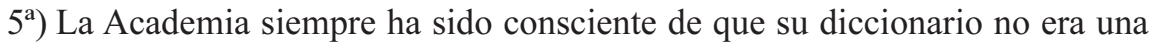
obra acabada y de que las tareas de «aumento» y de «corrección» no concluirían jamás; prueba de ello es que voces o acepciones, que habían sido despojadas de la abreviatura que las asignaba al campo de esta actividad profesional, han vuelto a recuperarla y la exhiben en el DRAE-2001 con marca de derecho (abrogación, abrogar, absolución de la instancia, auto, comparecer, contestación, dar fianza, declarante, institución de heredero, mejora, pedimento, queja, subsidiario, supervención...).

\section{REFERENCIAS BIBLIOGRÁFICAS}

Alvar Ezquerra, Manuel (1993): «El Diccionario académico en sus prólogos», en Lexicografia descriptiva, Barcelona, Biblograf, pp. 215-239.

Álvarez de Miranda, Pedro (2000): «La lexicografía académica de los siglos XVIII y XIX», en I. Ahumada Lara, ed., Cinco siglos de lexicografía del español. IV Seminario de lexicografía hispánica (Jaén, 17 al 19 de noviembre de 1999), Jaén, Universidad de Jaén, pp. 35-61.

AZORÍN FernÁndeZ, Dolores (2000): «La lexicografía académica en el siglo XVIII», en Los diccionarios del español en su perspectiva histórica, Alicante, Universidad de Alicante, pp. 159-199.

- (2001): «Salvá y la Academia Española: dos posturas frente a la recepción de los tecnicismos en el diccionario de la lengua», en M. Á. Esparza Torres, B. Fernández Salgado y Hans-Josef Niederehe, eds., Estudios de historiografía lingüística, Hamburg, Helmut Buske, II, pp. 777-788.

DA. Real Academia Española (1990 [1726-1739]): Diccionario de autoridades, Madrid, Gredos [ed. facsímil]. 
DRAE-1791. Real Academia Española: Diccionario de la lengua castellana reducido á un tomo para su mas fácil uso, Madrid, Viuda de Don Joaquin Ibarra.

DRAE-1970. Real Academia Española (1970 ${ }^{19}$ ): Diccionario de la lengua española, Madrid, EspasaCalpe.

DRAE-2001. Real Academia Española (200122): Diccionario de la lengua española, Madrid, EspasaCalpe.

HAENSCH, Günther (1997): Los diccionarios del español en el umbral del siglo XXI, Salamanca, Universidad de Salamanca.

Henríquez Salido, Ma do Carmo (2004): «La marca «forense» en el Diccionario de Autoridades», en C. Corrales Zumbado, et al., eds., Estudios de historiografía lingüística. Actas del IV Congreso Internacional de la SEHL, Madrid, Arco/Libros, I, pp. 763-773.

Real Academia Española: Nuevo tesoro lexicográfico de la lengua española, Madrid, Espasa [ed. en DVD-ROM].

RuhStAller, Stefan (2003): «Las obras lexicográficas de la Academia», en A. M. ${ }^{a}$ Medina Guerra, coord., Lexicografía española, Madrid, Ariel, pp. 235-261.

Zamora Vicente, Alonso (1999): Historia de la Real Academia Española, Madrid, Espasa-Calpe. 